\title{
INTERCONEXÕES DA GESTÃO PEDAGÓGICA NO MOODLE E A VISÃO DE PROFESSORES FORMADORES ATUANTES EM LICENCIATURAS
}

\author{
Fabiane da Rosa Domingues, PPGE, UFSM, fabirdfabiane@gmail.com \\ Adriana Moreira da Rocha Veiga, PPGE- CE, UFSM, adrianaufsm@gmail.com \\ Thais Pulgatti Trindade, PPGE, UFSM, thaistrindade.ufsm@hotmail.com
}

\begin{abstract}
Resumo. O artigo decorre de pesquisa, objetivando compreender como ocorre a apropriação e a integração das Tecnologias Digitais da Informação e Comunicação (TDIC), principalmente do Ambiente Virtual de Ensino Aprendizagem (AVEA) MOODLE pelos professores formadores dos cursos de Licenciatura da Universidade Federal de Santa Maria - UFSM. Trata-se de pesquisa qualitativa, do tipo estudo de caso, baseada em questionário on line a partir do Software Survey Monkey. Foram envolvidos os vinte e três (23) cursos de Licenciatura da UFSM, com a significativa participação de cem (100) professores formadores. Os resultados apontam que os professores formadores se apropriam e integram, ainda que sutilmente, algumas TDIC e recursos educacionais do MOODLE em sua prática pedagógica, que as metodologias utilizadas no processo ensino- aprendizagem tornam o professor gestor do processo formativo e desenvolver fluência tecnológica e pedagógica é o início de uma proposta inovadora, inerente às novas tecnologias.
\end{abstract}

Palavras-chave: AVEA MOODLE, docência superior, fluência tecnológica-pedagógica, gestão pedagógica e professor formador (PF).

\section{INTERCONNECTIONS OF PEDAGOGICAL MANAGEMENT IN MOODLE AND THE VISION OF TEACHERS EDUCATORS OF THE LICENCIATURES}

\begin{abstract}
The article is based on research, aiming to understand how the appropriation and integration of Digital Information and Communication Technologies (TDIC), mainly of the Virtual Environment of Teaching Learning (AVEA) MOODLE by the professors of the undergraduate courses of the Federal University of Santa Maria - UFSM. This is a qualitative research, of the case study type, based on an online questionnaire from the Software Survey Monkey. Twenty-three (23) UFSM undergraduate courses were involved, with a significant participation of hundred (100) teacher educators. The results show that the teacher educators appropriate and integrate, albeit subtly, some TDIC and educational resources of MOODLE in their pedagogical practice, that the methodologies used in the teaching-learning process make the teacher the manager of the training process and develop technological and pedagogical is the beginning of an innovative proposal, inherent in new technologies.
\end{abstract}

Keywords: AVEA MOODLE, higher teaching, technological-pedagogical fluency, pedagogical management and teacher educators $(P F)$.

\section{INTRODUÇÃO}

As grandes transformações sociais movidas pelo avanço tecnológico desafiam o contexto educacional, pois a cultura digital tornou-se parte do cotidiano. A inserção das tecnologias e mídias digitais na educação dá acesso ilimitado à informação e à comunicação, permitindo o seu uso integrado como recursos potencializadores de 
natureza sociocultural, portanto, podendo ser articulados como mediadores no processo ensino-aprendizagem. Consideramos a importância da apropriação de práticas educativas inovadoras, por exemplo, em Ambientes Virtuais de Ensino- Aprendizagem (AVEA) como no contexto da UFSM, com a institucionalização da Plataforma MOODLE (Modular Object Oriented Dynamic Learning Environment). No entanto, a legitimação das intenções institucionais depende da apropriação dos saberes pedagógicotecnológicos ${ }^{1}$, o que ainda é pouco visível nas práticas pedagógicas docentes.

A intensidade e avanço das inovações tecnológicas nos traz a urgência de compreendermos as relações e inter-relações na formação de sujeitos já inseridos na cultura digital. Essa compreensão nos leva ao tema do estudo, qual seja "a Gestão Pedagógica frente à docência nas licenciaturas e a convergência digital e tecnológica nos contextos da Educação Superior”.

O estudo decorre de uma pesquisa de especialização, recorte da pesquisa intitulada "Cultura de Convergência Digital e Tecnológica nos Cursos de Licenciatura da UFSM: É possível uma Conexão (Trans) Formativa entre a Educação Superior e a Educação Básica? ", desenvolvido pelo Grupo de Estudos sobre Educação na Cultura Digital e Redes de Formação - GPKOSMOS com financiamento do CNPq.

Neste recorte procuramos possíveis respostas ao seguinte problema de pesquisa: A Gestão Pedagógica se apropria, organiza e integra as Tecnologias Digitais de Informação e Comunicação (TDIC) nos cursos de Licenciatura da Universidade Federal de Santa Maria (UFSM)? Para tanto, objetivamos neste artigo, mostrar se está ocorrendo ou não a apropriação das TDIC pelos professores formadores dos cursos de Licenciatura e a integração do Ambiente Virtual de Ensino-Aprendizagem (AVEA) MOODLE nas práticas pedagógicas ofertadas nestes cursos e, ainda, se a organização da gestão pedagógica das licenciaturas visa à fluência tecnológica e pedagógica para utilizar o AVEA MOODLE como apoio didático-pedagógico no ensino presencial.

Definimos "gestão pedagógica" a partir de aportes trazidos por Libâneo (2002), Lück (2009), Lunardi (2012), conceituando gestão pedagógica/do pedagógico, abrangendo as ações atreladas: à organização didático- metodológica, à tomada de decisões, à participação, aos saberes e desafios docentes compartilhados e à autorreflexão sobre a ação realizada nos contextos educativos, desde a seleção dos materiais, conhecimento sobre o material até a aplicação e sucesso dos mesmos no processo ensinoaprendizagem.

Agregamos a essa configuração de saberes do professor formador, a fluência pedagógica e tecnológica e os Recursos Educacionais Abertos (REA) destes ambientes digitais. Ser fluente, segundo Kafai e colaboradores (1999), é desenvolver habilidades, ter conhecimento para além da máquina e saber explorá-la, utilizá-la e apropriá-la conforme o contexto inserido, é dotar saberes para compartilhar novos saberes.

\section{APORTE TEÓRICO}

\subsection{Trajetória de ser formador de professor e imigrante digital}

Francesc Imbernón (2011), relaciona a formação de professores, uma formação

\footnotetext{
${ }^{1}$ Danilo Ribas Barbiero (2015), propôs o constructo "Saberes pedagógicos tecnológicos”, os quais ampliam a relação docente com a cultura tecnológica e com a web como espaço para a produção de conhecimentos. 
profissional, ao conhecimento profissional e à especificidade da profissão docente. Entende que o conhecimento do professor tem uma natureza polivalente, construído e reconstruído de forma permanente durante o seu percurso profissional, na relação teoria/prática.

Consideramos a contribuição de Freire (2011), no que se refere aos saberes necessários ao professor para pensar a sua prática pedagógica. Freire (1991, p. 71) afirma que "ninguém começa a ser professor numa certa terça-feira às $4 \mathrm{~h}$ da tarde [...] Ninguém nasce professor ou marcado para ser professor. A gente se forma como educador permanentemente na prática e na reflexão, mas necessário à prática pedagógica". O que define o professor a partir das experiências e vivências na prática pedagógica.

Podemos ressaltar a grande responsabilidade do professor formador em articular teorias e práticas inovadoras e pertinentes para a constituição do "ser professor" diante das tecnologias digitais e educacionais. Tendo a linguagem digital como uma das novas linguagens desafiadoras do processo formativo docente nos cursos formadores de professores, no caso, as Licenciaturas da UFSM; os professores em formação poderão aprender mediados por tecnologias cognitivas, compreendendo sua importância e preparando-se para a atuação junto às novas gerações, já inseridas na cultura digital.

\title{
2.2 O professor formador como gestor pedagógico das TDIC
}

A gestão, compreendida como tomada de decisão, organização, direção e participação (LÜCK, 2009) ocorre em todos os âmbitos das instituições educacionais. Para Libâneo (2000), a gestão está diretamente relacionada com os princípios de democratização e participação, implicando na busca de objetivos comuns pelos profissionais da educação, onde cada um assume a sua parte no planejamento e desenvolvimento das suas práticas para alcançarem um objetivo geral coletivo.

Apesar dos autores citados referirem-se à gestão pedagógica ligada à educação básica, no ensino superior as atribuições docentes podem ser compreendidas a partir do mesmo referencial. Todo curso de graduação possui o seu Projeto Pedagógico de Curso (PPC), onde são explicitados os objetivos do curso, o papel que o professor deve assumir, bem como o perfil do aluno que se pretende formar, relacionando com as áreas de atuação. Desse modo, cabe ao professor desenvolver o seu trabalho de acordo com o projeto de curso. Nesta direção, concordamos com Lunardi (2012):

\begin{abstract}
A gestão pedagógica, também, está ancorada nos saberes da docência que podem ser traduzidos pelo conhecimento aprofundado de um dado campo de estudos; pela produção e manejo de materiais didáticos; pelo domínio de instrumentos metodológicos; pela clareza quanto à opção epistemológica e quanto ao nível cognitivo e intelectual esperado dos alunos durante as situações de aprendizagem; pela criatividade e bom senso na elaboração de situações que desafiem o pensamento e que produzam a novidade (p. 96).
\end{abstract}

A gestão pedagógica é compreendida como o processo que envolve todos os âmbitos da docência, desde os saberes didáticos, visão social e compreensão das possibilidades e limitações de cada contexto e se constrói à medida que o professor se compromete com um projeto de ensino, organizando e articulando saberes necessários para a formação de seus alunos e, consequentemente, para a sua própria formação.

Nesse sentido, Libâneo (2000) nos apresenta a produção da aula como a gestão pedagógica por excelência, ou seja, o ensino como uma modalidade da gestão pedagógica. 
Pensar o professor formador como Gestor Pedagógico ${ }^{2}$ diante das tecnologias educacionais no Ensino Superior e em meio às mudanças no contexto social, requer que se articule a organização didático-metodológica e práticas que se tornem significativas no processo de formação inicial. Com a inserção das tecnologias digitais a educação vem sendo repensada do ponto de vista didático, a partir da mediação das TDIC como instrumentos de mediação sociocultural no processo ensino-aprendizagem.

A intensidade e avanço das inovações tecnológicas, envolve compreendermos as relações entre a formação dos sujeitos inseridos nesta ambiência transformativa e humano-tecnológica, a formação inicial dos licenciados, a formação permanente ou continuada dos professores formadores e a integração das TDIC.

Complementando, a ambiência em que se exerce a docência é uma configuração resultante do impacto das condições externas de trabalho sobre o mundo interior dos docentes, agindo como força gerativa ou restritiva no processo de transformação em direção ao bem-estar e autorrealização profissional. (MACIEL, 2009). Consequentemente "pensar a formação implica compreendê-la como um processo sistemático e organizado, envolvendo tanto os sujeitos que estão se preparando para a docência, quanto àqueles que nela já estão engajados. (BOLZAN; ISAIA; MACIEL, 2013, p. 7).

A situação-limite de saber utilizar e se apropriar de um recurso tecnológico e midiático em meio ao processo educativo converge com as concepções freireanas de práxis dialógico-problematizadora (FREIRE, 1987), cujo foco é a dialogicidade e a interação colaborativa para o compartilhamento do conhecimento a partir das diferentes visões de mundo dos sujeitos envolvidos no processo.

A partir da superação das situações-limites, os professores e os estudantes conseguirão compreender a importância e articular processos formativos para $\mathrm{o}$ desenvolvimento da Fluência Tecnológica, onde saberão se apropriar do MOODLE e de suas funções básicas: ligar o computador, acessar a máquina, conhecer e integrar os recursos, disponibilizar materiais, recriar novos e compartilhar em formato livre e aberto o que foi produzido.

\section{PERCURSO METODOLÓGICO}

A pesquisa se caracterizou como qualitativa do tipo descritiva, com levantamento de dados a partir do software Survey Monkey. Assim, para a realização do estudo utilizamos um questionário com questões fechadas, abertas e dependentes. Foram convidados para participar da pesquisa, 469 professores formadores dos Cursos de Licenciatura - CL, da UFSM, dos quais obtivemos um retorno significativo de 100 respondentes, mais de $20 \%$ do quadro docente das licenciaturas.

Após a construção das questões e busca do endereçamento, foi realizado o cadastramento dos e-mails e a divulgação do questionário para os sujeitos. Nesta divulgação foi encaminhado um convite para participar da pesquisa, respondendo o questionário com prazo de trinta (30) dias úteis. A ferramenta Survey Monkey sempre

\footnotetext{
2 O professor é sempre Gestor Pedagógico, pois a conceituação de gestão pedagógica envolve ações de organização didático-metodológica, tomada de decisões, participação proativa, desde a seleção dos materiais, conhecimento sobre o material até a aplicação e sucesso dos mesmos no processo ensinoaprendizagem.
} 
identificava quem acessava o questionário, quantas perguntas respondiam e a quem ainda não havia respondido automaticamente poderia ser reenviado o convite-lembrete.

Disponibilizamos o convite a todos os Centros de Ensino da UFSM - Campus Santa Maria e aos vinte e três (23) cursos de licenciatura, incluindo o Programa Especial de Graduação que licencia profissionais com bacharelado, operando com ensino híbrido, ou seja, $50 \%$ na Plataforma MOODLE, o que o torna singular no conjunto dos cursos abordados pela pesquisa.

\section{ANÁLISE E DISCUSSÃO DOS ACHADOS}

Refletindo acerca da gestão pedagógica diante das tecnologias educacionais, o AVEA MOODLE, é importante retomarmos o sentido do termo gestão, citado neste estudo como a ação, reflexão e organização didático-metodológica, a busca por conhecimentos e estratégias pedagógicas para enriquecer a prática educativa frente a seus desafios.

Buscando nos aproximarmos das respostas para os objetivos deste estudo, elaboramos da questão 5 à 10, perguntas referentes aos recursos e equipamentos tecnológicos disponíveis na UFSM, a utilização do MOODLE no ensino presencial, como este AVEA é recebido pelos docentes formadores e a importância da fluência pedagógicatecnológica para melhor explorar esta tecnologia educacional a fim de construir e [re] construir a docência superior nos CL da UFSM diante da convergência digital e tecnológica.

Dessa forma, a questão 5 elucidava: Quais os equipamentos tecnológicos você encontra disponíveis na UFSM para planejamento e elaboração de materiais didáticos? Dispomos de seis opções entre elas, Data show, Lousa digital, Notebook, Filmadora, Câmera Digital, Computador e outros.

Como demostra a figura 4 , a seguir, os três principais equipamentos tecnológicos disponibilizados e que são encontrados com maior facilidade no contexto dos CL da UFSM, são: o computador, 97,50\%; data show, $92,50 \%$ e notebook, $38,75 \%$.

Figura 4: Equipamentos tecnológicos disponíveis nos CL da UFSM.

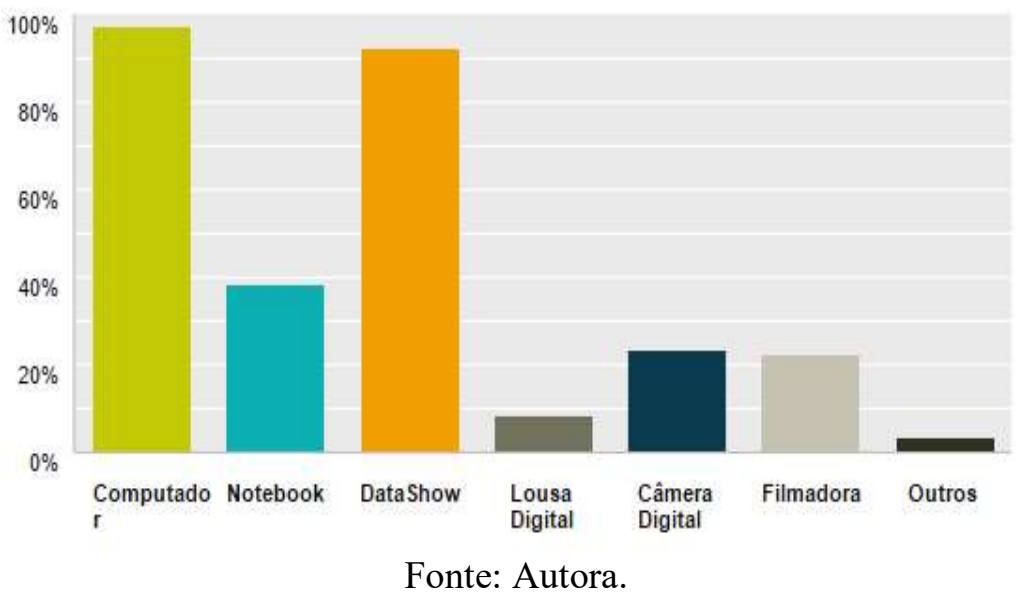

Na questão 6, perguntamos “Com que frequência você utiliza/utilizou o Ambiente 
Virtual de Ensino-Aprendizagem (AVEA) - MOODLE em suas disciplinas de modalidade presencial? Observemos a figura 5:

Figura 5: Frequência de utilização do AVEA MOODLE nos CL UFSM.

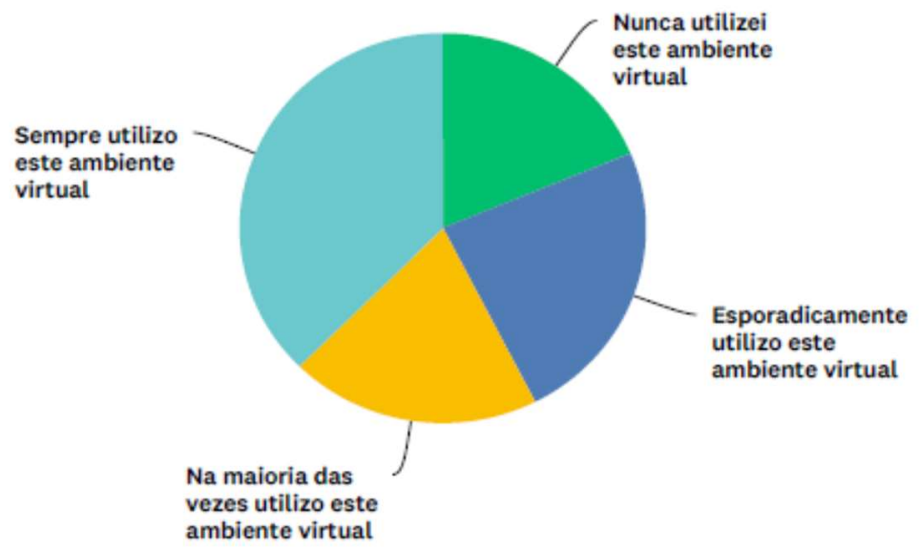

Fonte: Autora.

Consideramos que $42,50 \%$ dos participantes nunca utilizaram ou esporadicamente utilizam este ambiente virtual em suas disciplinas na modalidade presencial. Somente $20 \%$ dos docentes relatou que utilizam na maioria das vezes o AVEA e outros $37,50 \%$ relataram que sempre utilizam este ambiente em suas disciplinas.

Os achados nos levam a refletir e questionar quais as razões de pouca utilização. Desconhecimento, pouca prática, formação tecnológica, interface difícil de manusear, tempo?

Continuamos buscando responder em parte o questionamento supracitado, seguimos na questão 7 com algumas opções aos respondentes ao seguinte questionamento: Se utilizou com pouca frequência o Ambiente Virtual de EnsinoAprendizagem (AVEA) - MOODLE, quais as razões?

$\mathrm{Na}$ figura 6, a seguir, as respostas:

Figura 6: Razões da pouca utilização do AVEA MOODLE.

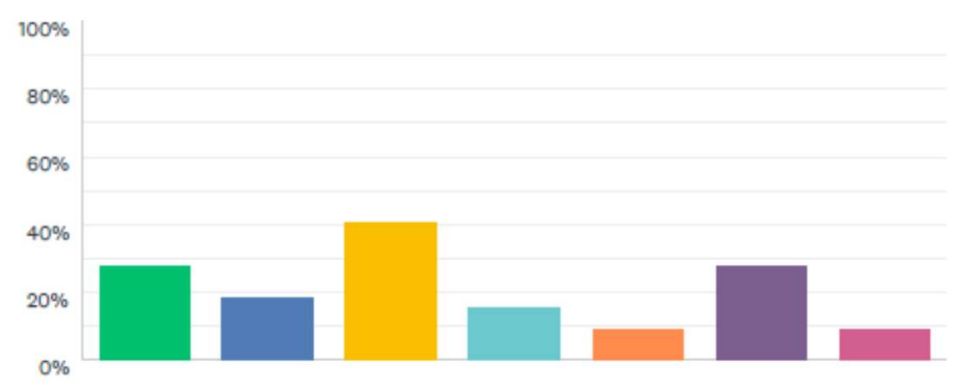


Prefiro elaboração e recebimento de trabalhos impressos

Considero uma ferramenta complicada

Não conheço a ferramenta o suficiente e prefiro năo ficar dependente de outra pessoa

Não sei como organizar e disponibilizar o conteúdo no Moodle

Năo consigo pensar em uma metodologia para atender o estudante utilizando o Mood

Há muita carga de trabalho para estruturaçăo de uma disciplina

Devido as constantes falhas do servidor que gerencia a rede do Moodle

Fonte: Autora.

A alternativa que obteve mais respostas foi a opção 3, ilustrada em cor amarelo escuro, na qual 40,63\% dos docentes participantes deste estudo, apontaram que "não conhecem a ferramenta o suficiente e preferem não ficar dependentes de outra pessoa para o desenvolvimento das atividades. $\mathrm{Na}$ opção ilustrada em cor verde e roxo apontam $28,13 \%$ docentes que preferem elaboração e recebimento de trabalhos impressos e, ainda, há muita carga de trabalho para estruturação de uma disciplina no AVEA MOODLE. Na opção de cor azul escuro, 18,75\% dos docentes relataram que o MOODLE é considerado uma ferramenta complicada. As demais cores, somam 12,49\%, o posicionamento dos docentes que dizem não saber organizar e disponibilizar o conteúdo no $M O O D L E$, não conseguem pensar uma metodologia para atender o estudante utilizando este ambiente e que não utilizam devido às constantes falhas do Servidor de Internet que gerencia a rede que ativa o MOODLE da UFSM.

$\mathrm{Na}$ questão 8, damos continuidade ao mesmo contexto reflexivo, trazendo um enunciado sobre Gestão Pedagógica e após questionando os docentes em relação à interface do $M O O D L E$, se é ou não de fácil manuseio e interação:

Pensando acerca da Gestão Pedagógica como sendo todas as ações atreladas à organização didática-metodológica, tomada de decisões, participação, saberes, possibilidades, desafios compartilhados, integração, convergência e autorreflexão sobre a prática desenvolvida nos contextos educativos, o AVEA MOODLE é um ambiente de fácil acesso, manuseio e domínio dos recursos educacionais para integrá-los em suas práticas pedagógicas?

As respostas encontram-se na figura 7, a seguir:

Figura 7: Grau de concordância dos PF sobre AVEA MOODLE como um ambiente de fácil acesso, manuseio e domínio dos recursos educacionais.

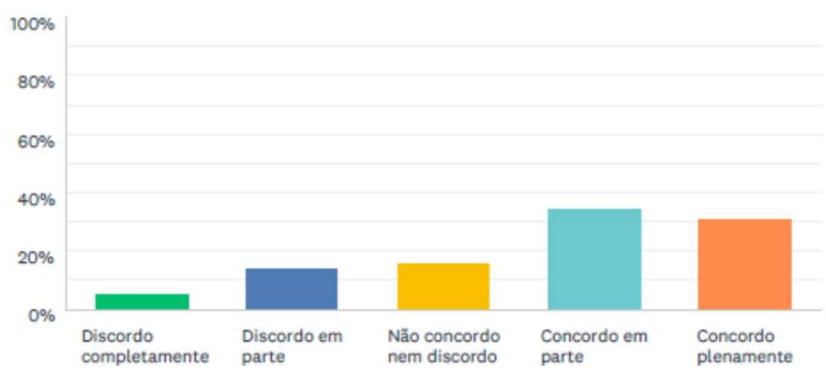

Fonte: Autora.

O total de $34,62 \%$ dos participantes relatou que concordam em partes que o 
AVEA MOODLE é um ambiente de fácil acesso, manuseio e que abrange recursos educacionais potencializadores para a sua prática pedagógica; 30,77\% concordam plenamente. Ou seja, apenas 35 docentes dos 100 participantes do estudo, concordam plenamente com a questão elucidada acima. Enquanto 19,23\% dos docentes discordam plenamente ou em parte que este ambiente seja uma plataforma com interface diferenciada; quanto aos recursos educacionais, ressaltam que não é um AVEA que o usuário tenha facilidade em acessar e manusear. E os outros $15,38 \%$ não concordam e nem discordam com a questão.

A questão 9, aborda a capacitação, formação ou fluência dos docentes em relação a sua prática pedagógica e a utilização do ambiente $M O O D L E$ no ensino presencial. E provoca reflexão acerca dos conhecimentos diante das mídias digitais, tecnologias educacionais e, portanto, do AVEA MOODLE. Esta questão está formulada da seguinte maneira: Fluência pedagógica e tecnológica são princípios basilares da performance docente com tecnologias educacionais. É um processo contínuo de aperfeiçoamento e aprendizagem. Em uma escala de 0 (discordo totalmente) a 10 (concordo totalmente), indique o grau de fluência que você acredita que já desenvolveu/desenvolve frente ao AVEA MOODLE.

Observemos a Figura 8 a seguir:

Figura 8: Grau de Fluência pedagógica e tecnológica.

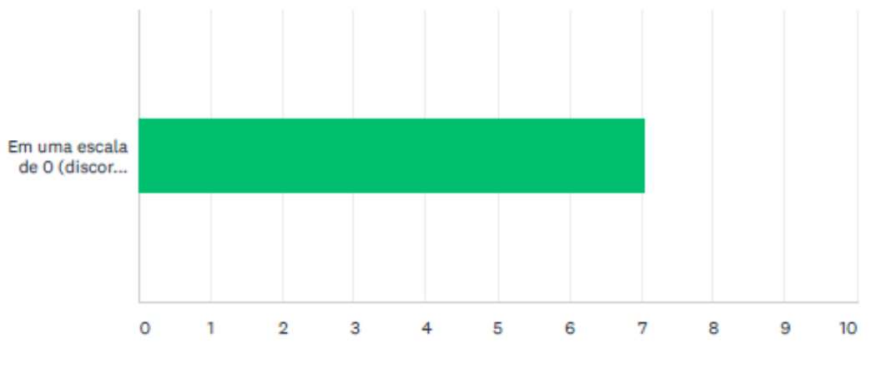

Fonte: Autora.

Percebemos que 21 professores recusaram participar desta questão, sendo assim, do total de 100 participantes, 79 docentes participaram. Obtivemos nesta escala a média 7, este foi o grau apontado pelos docentes quanto ao desenvolvimento da fluência pedagógica e tecnológica diante do AVEA MOODLE.

A última questão, "soa" como provocativa e autorreflexiva em relação ao saber docente do ser professor formador e a integração e convergência das tecnologias educacionais. A questão 10 então está elucidada como: Você professor formador teve ou considera importante ter uma formação "pedagógica-tecnológica" para conhecer, apropriar-se e integrar as tecnologias em sua prática docente?

A opinião dos PF sobre a Formação Pedagógica-Tecnológica demonstrou que 94,94\% dos docentes já tiveram ou consideram importante ter uma formação "pedagógica-tecnológica" para conhecer, apropriar-se e integrar as tecnologias em sua prática docente. Ainda tivemos um percentual de 5,06\% que não tiveram formação/ capacitação ou que não consideram importante ter no momento. 
Por isso, a importância deste estudo propor um processo dialógico, formativo e de escuta aos professores formadores de professores em relação aos seus saberes sobre as tecnologias educacionais e um programa de formação continuada para atender às necessidades identificadas pelos docentes.

\section{APONTAMENTOS FINAIS}

Podemos observar que os professores formadores nas licenciaturas da UFSM, se apropriam de algumas mídias digitais e TDIC encontradas e disponibilizadas nos Centros de Ensino dessa instituição, no entanto, percebemos que esta apropriação ainda é muito incipiente, isto porque os docentes procuram utilizar estas tecnologias na interface mais simples, por vezes, porque desconhecem as demais funcionalidades.

A maioria apontou que o MOODLE é de difícil navegabilidade e apresenta interface não atrativa e motivadora para o grupo de estudantes, futuros professores, provavelmente na Educação Básica, em que as novas gerações esperam por uma abordagem diferenciada da tradicional. Também destacaram que a organização da gestão pedagógica caminha lentamente, pois há tentativas dos professores em aprimorar conhecimentos sobre a tecnologia e, portanto, de saber como integrá-la em sua prática.

A gestão educacional é chamada democraticamente a "trabalhar a escuta" para com os sujeitos inseridos nos contextos educativos, conhecer suas especificidades, potencialidades e dificuldades em meio ao processo de ensino permeado pelas tecnologias em rede, neste caso, o AVEA MOODLE.

A partir disso, é possível articular processos formativos para o desenvolvimento da Fluência Tecnológica, onde saberão se apropriar do MOODLE, ligar o computador, acessar a máquina, conhecer e integrar os recursos, disponibilizar materiais, recriar novos e compartilhar em formato livre e aberto o que foi produzido. E a Fluência Pedagógica preconiza ao professor que desenvolva um olhar inusitado para o modo de ensinar a sua disciplina, desenvolvendo recursos mediados pelas tecnologias.

No entanto, obtivemos respostas positivas em relação à apropriação e integração do AVEA para possível convergência digital e tecnológica nos CL. Os docentes que já utilizaram e/ou utilizam o MOODLE como apoio didático-pedagógico no ensino presencial relataram não conhecer profundamente as ferramentas e recursos que o mesmo suporta, mas ressaltaram a necessidade de inovar suas práticas diante da cultura digital, na qual os professores em formação se encontram cotidianamente e que posteriormente estarão diante dos estudantes de uma Educação Básica imersa nesta mesma cultura digital e tecnológica. Mais de $90 \%$ dos docentes que participaram desta pesquisa elucidaram a importância da formação continuada, de oportunidades e da "gestão da disponibilidade" para a realização da mesma. Concordaram entre si que é necessário no atual cenário educacional ser fluente tecnologicamente.

A partir dos dados analisados, observamos que alguns dos professores formadores ainda precisam compreender que cada vez mais o contexto educacional está se reformulando do ponto de vista didático-metodológico. Dessa forma torna-se necessário buscar alternativas motivadoras para a prática docente. Atrelar as tecnologias e seus recursos ao âmbito das ações educativas, mais precisamente o MOODLE, seria um aliado potencializador das práticas pedagógicas, pois tem capacidade de integrar diversas linguagens, Recursos Educacionais Abertos- REA e atividades de estudo hipermidiáticas.

Dessa forma, fica evidente que, pensando nas possíveis experiências dos 
professores em formação, na medida em que aprendem mediados por tecnologias cognitivas, compreendendo a sua importância, se preparam para a atuação na Educação Infantil, Ensino Fundamental e Ensino Médio, junto às novas gerações já inseridas na cultura digital. Papel este fundamental e desempenhado pelos professores formadores, por isso a importância da formação tecnológica e da gestão pedagógica se auto organizarem para este processo ser viabilizado.

No entanto, é preciso esclarecer que a cultura universitária tradicional, pautada em aulas expositivas e materiais impressos, precisa ser revertida por já não responder às características da Era Digital. O professor deve desejar-se (co) autor, (co) desenvolvedor, como propõe o movimento REA, aliado à autoformação em busca da Fluência Tecnológica e Pedagógica, pertinente ao exercício da sua autonomia didático-política na produção dos recursos e tarefas de estudo.

\section{REFERÊNCIAS:}

BOLZAN, D. P. V.; ISAIA, S. M. A.; MACIEL, A. M. R. Formação de professores: a construção da docência e da atividade pedagógica na Educação Superior. Rev. Diálogo Educ., Curitiba, v. 13, n. 38, p. 49-68, jan. /abr. 2013.

FREIRE, Paulo. Pedagogia da autonomia: saberes necessários à prática educativa. 13. ed. Rio de Janeiro: Paz e Terra, 2011.

.Pedagogia do Oprimido. 17. ed. Rio de Janeiro: Paz e Terra, 1987.

.A Educação na Cidade. São Paulo: Cortez, 1991.

IMBERNÓN, Francisco. Formação docente profissional: formar-se para a mudança e a incerteza. 9 ed. São Paulo: Cortez, 2011.

KAFAI, Y. et al. Being Fluent with Information Technology, 1999. Disponível em: http://www.nap.edu/catalog.php?record id=6482; . Acesso em: 06 janeiro 2014.

LIBÂNEO, J.C. Pedagogia e pedagogos, para quê? 3. Ed. São Paulo: Cortez, 2000.

. Ainda as perguntas: o que é pedagogia, quem é o pedagogo, o que deve

ser o curso de Pedagogia" IN: PIMENTA, S. G. (Org.) Pedagogia e pedagogos:

caminhos e perspectivas. São Paulo: Cortez, 2002.

LÜCK, Heloísa. Concepções e processos democráticos de gestão educacional.

Petrópolis, RJ: Vozes, 2009. (Vol. II).

LUNARDI, E. M. Qualidade e Gestão Pedagógica. In: MOROSINI, M e FRANCO.

Qualidade da educação superior dimensões e indicadores. Porto Alegre: EDIPUCRS, 2012, p. 277-291.

MACIEL, Adriana Moreira da Rocha. O processo formativo do professor no ensino superior: em busca de uma ambiência (trans) formativa. In: ISAIA, Silvia Maria de Aguiar; BOLZAN, Dóris Pires Vargas Bolzan; MACIEL, Adriana Moreira da Rocha (Org.). Pedagogia Universitária tecendo redes sobre a educação superior. Santa Maria: Editora UFSM, 2009, p.63-77. 